\title{
Ato, atalho e vento: as fórmulas de páthos na história do cinema
}

\author{
Gabriel Malinowski' \\ I - UERJ \\ Rio de Janeiro (RJ), Brasil
}

Resumo: O artigo tematiza o conceito de pathosformel, de Aby Warburg, na leitura do filme "Ato, atalho e vento" (2014), de Marcelo Masagão. Assim como no conhecido "Nós que aqui estamos, por vós esperamos" (1999), Masagão realiza, nessa nova proposta, uma colagem com 143 filmes. Uma característica marcante na montagem de "Ato, atalho e vento" é a aproximação de certos trechos por semelhanças, seja na temática, na forma, ou ainda nos gestos. Assim, temos espécies de sequências que recobrem a repetição de formas carregadas de significados, tais como o ato de "ser fotografado" ou de "fugir". Seguindo a visão warburguiana, poderíamos notar nessas sequências montadas elementos antropológicos de nossa modernidade através das fórmulas de páthos que os filmes representam e sugerem pelo encadeamento de imagens. Pretendemos, assim, verificar as relações entre gesto, cinema e pathosformel para analisar com rigor teórico o filme de Masagão. Além do repertório teórico de Warburg, serão convocados comentadores que repensam a teoria warburguiana na chave cinematográfica, como Giorgio Agamben, Philippe Alain-Michaud e Georges Didi-Huberman.

Palavras-chave: Marcelo Masagão; montagem; Pathosformel; Aby Warburg.

Abstract: Ato, Atalho e Vento": pathos formula in history of cinema - The paper thematizes the concept of pathosformel, by Aby Warburg, in the reading of the film Ato, atalho e vento (2014), by Marcelo Masagão. Just as in the known Nós que aqui estamos, por vós esperamos (1999), Masagão makes, in this new proposal, a collage with 143 films. A striking feature in the montage of Ato, atalho e vento is the approximation of certain passages by similarities, whether in thematic, in form, or even in gestures. Thus we have species of sequences that cover the repetition of forms loaded with meanings, such as the act of "being photographed" or "escaping." Following the Warburgian view, we could note in these sequences anthropological elements of our modernity through the pathos formula that the films represent and suggest by the chain of images. We intend, therefore, to notice the relations between gesture, cinema and pathosformel to analyze with theoretical rigor the film of Masagão. In addition to Warburg's theoretical repertoire, commentators will be invited to rethink the Warburgian theory in the cinematographic key, such as Giorgio Agamben, Philippe Alain-Michaud and Georges Didi-Huberman.

Keywords: Marcelo Masagão; montage; Pathosformel; Aby Warburg. 


\section{Introdução}

A apropriação e a remontagem de imagens de arquivo, derivadas do cinema, da televisão, de acervos públicos ou privados, tem sido a aposta de algumas produções audiovisuais recentes, e acompanham um interesse renovado pelo arquivo de modo geral no campo da arte, com suas possibilidades memorialísticas e estéticas. Luiz Cláudio da Costa afirma que "desde os anos 60, o arquivo é prática e metáfora constantes nas artes do Ocidente, incluindo os países periféricos." (COSTA, 2014, p. 23). No campo audiovisual, a nomenclatura que geralmente é atribuída a essas produções, como filme de montagem, filme-ensaio, filme de arquivo, tenta identificar essas realizações que, muitas vezes, borram as barreiras da ficção e do documentário, do gênero e da narrativa.

Marcelo Masagão, realizador paulistano do conhecido Nós que aqui estamos, por vós esperamos (1999), seu primeiro longa-metragem, renova a prática do filme de montagem em Ato, atalho e vento (2014). Ao longo de 70 minutos, Ato, atalho e vento apresenta uma colagem de trechos de 143 filmes. Uma característica marcante na montagem é a construção de (in)certos blocos temáticos que reforçam formas e gestos. Assim, os planos são aproximados por afinidades dos elementos estéticos e/ou das ideias correlacionadas. Porém, isso diz muito pouco sobre o filme. Apesar dessas informações gerais, trata-se de um filme complexo em sua tessitura, que muitas vezes pode deixar o espectador perplexo com o desenrolar das imagens. Essa dificuldade analítica é diagnosticada por Jean-Claude Bernadet em um texto reflexivo sobre o filme: "a que realmente estou assistindo? Que objeto audiovisual é esse?"1. O objetivo deste artigo é levantar possíveis respostas a essas questões.

Nossa proposta é fazer uma leitura do filme com base no referencial teórico do historiador de arte Aby Warburg (1866-1929), utilizando, sobretudo, o seu conceito de Pathosformel. O filme de Masagão possui estratégias e efeitos que dialogam com o pensamento e a metodologia de Warburg em relação às imagens. O projeto Atlas Mnemosine, particularmente, tido por teóricos como Philippe-Alain Michaud como um dos mais fascinantes e enigmáticos objetos na história da arte contemporânea, traz questões em relação à montagem que também se verificam no filme. Não se trata, certamente, de uma comparação que estende o pensamento de Warburg na proposta de Masagão de modo apaziguado e excessivamente direto. Tentaremos expor, ao menos de modo pontual, certas inadequações entre a teoria e o filme. A ideia central, contudo, é explorar algumas características e efeitos das apropriações feitas por Masagão com o pensamento de Warburg e, ao mesmo tempo, renovar a leitura crítica warburguiana a partir de um instigante objeto de arte contemporâneo.

\section{Cinema, gesto e Pathosformel}

Em Notas sobre o gesto, Giorgio Agamben faz uma curiosa abordagem entre o cinema e os gestos. Para o autor, o interesse empírico pela gestualidade do homem

1 Cf. Texto no blog de Jean-Claude Bernadet. Disponível em: http://outraspalavras.net/jcbernardet/author/jeanclaude/ 
no final do século XIX, como os estudos de Gilles de La Tourette sobre o andar, bem como os primeiros experimentos cinematográficos, são característicos de uma sociedade que perdeu os seus gestos: "uma época que perdeu seus gestos é, por isso mesmo, obcecada por estes" (AGAMBEN, 2008, p. 11). O autor sugere que o estilo de vida frenético da modernidade acabou por obliterar a desenvoltura gestual. Para Agamben, na virada do século XIX para o XX, "todos tinham perdido o controle de seus gestos, e caminhavam e gesticulavam freneticamente" (ibidem, p. 10). O interesse de Warburg por essa questão é inserido nesse momento histórico. Como enfatiza Agamben, as pesquisas de Warburg tinham no seu centro "o gesto como cristal da memória histórica" (p. 11). O cinema, nesse contexto, é entendido pelo autor como o local onde o gesto é reencontrado. Isso porque, mais do que a imagem, o elemento do cinema é o gesto: "o cinema reconduz as imagens para a pátria dos gestos" (ibidem, p. 12).

Em uma outra perspectiva, Philippe-Alain Michaud enfatiza que o gesto e as propriedade figurais do corpo no cinema são mais evidentes nos seus primeiros anos, quando a gestualidade ainda não é subserviente a uma função narrativa e ao cinema comercial. Para exemplificar, Michaud explora alguns trabalhos realizados pela empresa de Thomas Edison. No ano de 1894, por exemplo, um ano após Aby Warburg publicar seu primeiro ensaio, O nascimento de Vênus e A Primavera de Sandro Botticelli: uma investigação sobre as representações da Antiguidade no início do Renascimento italiano, TW Dickson, assistente de Edison, realiza diversas gravações no estúdio arrojado para os padrões da época chamado Black Maria. Dentre elas, uma gravação encomendada por um jornalista chamado Barnet Phillips, que serviria para ilustrar um artigo dedicado ao cinetoscópio de Edison. Publicado na revista Harper's Weekly, os fotogramas que compõem esse filme foram mostrados em nove faixas com nove fotogramas em cada uma delas. Na sequência de imagens, nota-se as modificações no rosto do ator Fred Ott durante um espirro. Na reportagem, o jornalista fazia uma decomposição minuciosa das diversas fases do espirro: premissas, sensação, nascente, primeira crispação, espera, intensificação, perda do autocontrole, explosão, êxtase, volta a si. Para Michaud, "os primeiros filmes de Dickson referiram-se à própria realidade da presença e às propriedades figurais do corpo cinematográfico como um momento de elucidação inaugural" (MICHAUD, 2013, p. 54).

Embora Aby Warburg não tenha tematizado a questão cinematográfica em sua trajetória intelectual, seu método dentro da história da arte apresenta, segundo o trabalho de Michaud, diversas relações epistemológicas com o cinema, na medida em que contempla, a seu modo, elementos e abordagens cinematográficos, como a montagem e o movimento. Ao longo de seu percurso teórico, Warburg se afasta do método estilísticoformal dominante na história da arte do final do século XIX e privilegia os movimentos de certas formas expressivas e gestuais que sobrevivem ao longo dos tempos. Para ele, as imagens são dotadas de uma pós-vida e estão em um movimento constante na humanidade. Daí as sobrevivências de certas figurações, conforme nomeia Georges Didi-Huberman (2013). 
Forma, assim, um trabalho iconográfico perpassado por interesses antropológicos, culturais e psicológicos. Para Warburg, a iconografia tende sempre à configuração de um problema histórico e étnico, apontando para um "diagnóstico de homem ocidental".

No Atlas Mnemosine, Warburg leva sua teoria para uma prática visual. Por meio de uma montagem de imagens (gravuras e fotografias, principalmente) em telas pretas, Warburg constrói, segundo Michaud, um objeto eminentemente cinematográfico. Isso porque, nesses blocos de imagens variadas, o "espectador" é convidado a circular entre os intervalos, a estabelecer sensações entre as imagens de diferentes períodos históricos. Para Michaud, Mnemosine era "inteiramente sustentada pela estética do movimento que, a partir do final do século XIX, exprimia-se no cinema nascente" (MICHAUD, 2013, p. 40).

No texto Introdução à Mnemosine, no qual aborda as características do projeto, Warburg afirma que "o Atlas Mnemosyne pretende, com seu material de imagens, ilustrar esse processo, que se poderia designar como uma tentativa de introjeção na alma dos valores expressivos pré-formados na representação da vida em movimento" (WARBURG, 2015, p. 364). Esses valores expressivos pré-formados na representação da vida referem-se ao que Warburg chama de Pathosformel, ou fórmulas de páthos. Carlinda Nuñez sintetiza o conceito de forma clara:

A expressão Pathosformel [...] designa gestos arquetípicos ligados a emoções tais como tristeza, alegria, medo, desespero, ódio, amor, esperança, desejo, frustração, audácia..., consagrados pela repetitividade e pela estratificação de experiências subjetivas. São imagens que condensam uma situação de caráter emocional (páthos) num cânone ao qual automaticamente remetem (formeln), já que de sua forma irrompe o conteúdo." (NUÑEZ, 2010, p. 55).

O conceito de Pathosformel, assim, condensa o núcleo das investigações de Warburg. "O indissolúvel entrelaçamento de uma carga emotiva e de uma fórmula iconográfica" (AGAMBEN, 2011, p. 132) é evidenciado nos estudos de Warburg desde os primeiros escritos sobre Boticcelli, quando o conceito ainda não está totalmente estabelecido. A aplicação do conceito, contudo, não se restringe ao campo da história da arte, e engloba os campos da cultura, da antropologia e da psicologia, em uma proposta complexa, uma "ciência sem nome" (AGAMBEN, 2008). Para Didi-Huberman (2013, p.173), "a Pathosformel, portanto, seria um traço significante, um traçado em ato das imagens antropomórficas do Ocidente antigo e moderno: algo pelo qual ou por onde a imagem pulsa, move-se, debate-se na polaridade das coisas".

\section{Ato, atalho e vento: um filme warburguiano}

Ato, atalho e vento é um filme de montagem, com a colagem de trechos de 143 longas-metragens, passando por obras de Fellini, Wenders, Bertolucci, Kiarostami, 
Kurosawa, entre outros diretores renomados. No início do filme, uma cartela que rola de baixo para cima de modo enviesado, como na abertura de Guerra nas Estrelas, traz um texto com as motivações do diretor-montador. A primeira informação é a de que o filme é fruto do encontro de 143 filmes com a conhecida obra de Freud, Mal-estar na civilização, e segue afirmando que: "este encontro se deu na cabeça do diretor, que da mesma forma que você, convive com uma montanha russa de conteúdos simbólicos e assombrações memóricas passeando ou se debatendo pelo corpo" (ATO..., 2014, grifo nosso). As similitudes com o pensamento de Warburg, que fazia histórias de fantasmas para gente grande, já pode ser evidenciada nesse texto. Segundo Agamben (2011, p. 137), o atlas de Warburg era "uma espécie de gigantesco condensador recolhendo todas as correntes energéticas que tinham animado e animavam ainda a memória da Europa, tomando corpo em suas 'fantasias'".

A cartela prossegue, e aponta para o estado de latência de algumas imagens que são despertadas (ou não) pelo encontro de outras cargas simbólicas. Ao final, conclui afirmando que "fazer um filme de fragmentos é antes de tudo, uma intenção de promover o encontro de 'coisas': tantas e tortas. É o desejo de ver entre as coisas". Cabe lembrar que "a 'ciência sem nome' buscada por Warburg é (...) 'uma iconologia do intervalo'" (AGAMBEN, 2011, p. 137). No Atlas, o intervalo é representado pelo espaço preto entre as imagens que se distanciam por séculos. No filme de Masagão, o intervalo entre os trechos é obviamente mais curto, e responde, no limite, à distância de algumas décadas entre os filmes. Essa característica, vale salientar, instala a montagem do filme de Masagão em um campo de forças muito mais circunscrito e circunstancial que o ambicioso Atlas de Warburg. Conforme nos lembra Didi-Huberman, o Atlas "passa de uma cultura a outra, de uma época a outra, do conhecido ao estranho, de um museu a outro, de uma igreja a uma biblioteca, de uma miniatura a um ciclo de afrescos, ou de um rosário a uma catedral" (DIDI-HUBERMAN, 2013, p. 385). Os gestos sequenciados por Masagão, de outro modo, são retirados de um conjunto restrito de filmes e recobrem apenas nossa herança gestual audiovisual e as marcas de uma cultura com pouco mais de um século.

Nota-se também que o Atlas trabalhado por Warburg, de 1924 até 1929, ano de sua morte, estava em constante alteração, com inserções e deslocamentos de figuras que ratificavam, na prática artística do projeto, um tópos teórico acerca das sobrevivências, desaparições e ressurgimentos de certos gestos/sentidos na história da arte. Ato, atalho e vento, ao contrário, é uma obra audiovisual acabada², e muito mais "imóvel", nesse sentido, apesar de suas imagens em movimento.

A sequência inicial faz a compilação de alguns planos que serão utilizados ao longo do filme, em um leitmotiv às avessas. Já nesse prólogo, mais do que uma construção de sentidos e de narrativa, o espectador saboreia uma espécie de devaneio pré-simbólico

2 Ainda que, entre a exibição do filme em festivais, Masagão tenha feito alterações. Segundo Bernardet: "Masagão vive alterando a montagem, a obra não se estabiliza". 
entre as imagens. Os planos são inseridos por uma imagem que se repete, de um monge tocando um sino. O toque da tora de madeira no sino libera as imagens, como se as despertassem de um sono. Ao final dessa sequência, a nave felliniana, de $E$ la nave va (1983) parte. É o início da jornada.

A montagem em Ato, atalho e vento constrói sequências que não são conformadas de modo narrativo, ou seja, não obedecem regras espaço-temporais. Trata-se de blocos que agrupam planos cinematográficos com certas semelhanças. Para Jean-Claude Bernadet, "o espectador percebe [...] que, dentro dos blocos, os planos se organizam por encadeamento de movimentos, composição ou oposições". O que Bernadet chama de movimentos são, com efeito, formas e gestos similares, que endossam a percepção de certa repetição com diferença. A imagem de $E$ la nave va, por exemplo, é mesclada com imagens de outros transportes modernos, que reforçam uma ideia de progresso. A sequência culmina com uma montagem instigante que conecta a Torre Eiffel parisiense às Torres Gêmeas, de Nova lorque. A montagem e o desvio das imagens é uma estratégia de estranheza que arma novos jogos espaço-temporais e simbólicos e altera nosso olhar. Algo se passa no entre, no intervalo, nos atalhos que o filme constrói.

Relacionemos essa proposta ao título do filme, que carrega algumas pistas importantes acerca daquilo que vemos. Ato, atalho e vento é um título que certamente chamaria a atenção de Warburg. Como afirma Etienne Samain, Warburg compreendia as imagens não como "meros 'objetos', nem apenas cortes no tempo e golpes no espaço", mas como “'atos', memórias, questionamentos, [...] visões e prefigurações" (SAMAIN, 2011, p. 40). No filme de Masagão, as imagens também são atos, ou seja, ações no tempo, e também parte de um todo (como na denotação teatral). O ato é a incandescência de formas e movimentos que, em justaposição, leva o espectador ao seu próprio universo de duração das imagens.

Há também um ritmo musical importante nas composições que tornam os blocos mais evidentes, criando ambiência para as imagens. A música funciona como um mecanismo que condiciona a intensidade e a duração dos planos. De certa maneira, a música está implicada no movimento do filme, ela alimenta a função poética do vento que dá título ao filme. $\mathrm{O}$ vento serve como uma metáfora para o movimento das imagens que, postas em contato e relação, conformam certos sentidos.

A força expressiva do vento aparece também em Warburg. Em seu primeiro trabalho publicado, a temática gira em torno da figuração do movimento em duas pinturas de Botticelli, O Nascimento de Vênus e A Primavera (2015). Warburg investiga as relações entre a representação das roupas, vestimentas e cabelos esvoaçantes, com algumas concepções da literatura poética e da Teoria da Arte na Antiguidade. Já no início de sua análise, sugere a confluência de trechos de um poema de Poliziano (1454 - 1494) com a figura dos dois ventos que voam sobre as ondas, na parte esquerda de O Nascimento de Vênus, e impelem a deusa até a margem. O vento atuaria, tanto no poema de Poliziano quanto na pintura de Botticelli, como um elemento que confere o movimento dos trajes, dos cabelos, e possibilita a expressão de certas formas patéticas. 
A Pathosformel no filme de Masagão parece ser um aspecto central, e que pode nos ajudar a responder a indagação proposta por Bernadet acerca do que é o filme. Se percebermos certas partes do filme como espécies de tableaux, notaremos que está em jogo ali certas formas expressivas colocadas em série. Os atos de se olhar no espelho, de ser fotografado, de velar um morto, de contemplar uma paisagem, de se enamorar são explorados enquanto fórmulas, que se repetem e expressam emoções. Obviamente, o filme complexifica essa estratégia, inserindo também formas não patéticas, como a belíssima sequência de esferas e imagens relacionadas a formas circulares. Entretanto, as expressões de emoções e sentimentos pelos gestos são predominantes.

Em certo trecho da resenha de Bernadet (2014, n.p.), o crítico resvala nessa abordagem. Trata-se da parte final do texto, quando reflete acerca das emoções que o filme suscita e a dificuldade em aplicar palavras a elas:

O importante dessa emoção, além da sua densidade, é o "de não se sabe o quê". Pois não tem como lhe aplicar palavras. Pode se falar em emoção arcaica, em "Freud", em "mistério", na tentativa de usar palavras para falar da relação com o filme. Talvez não haja outra possibilidade de falar desse filme senão falar na relação. Ato, Atalho e Vento está além do verbalizável, a obra não se deixa capturar por palavras.

Warburg costumava dizer que o Atlas era uma "espécie de gigantesco condensador recolhendo todas as correntes energéticas que tinham animado e animavam ainda a memória da Europa, tomando corpo em suas fantasias". (AGAMBEN, 2011, p. 137). Tal iconologia, posta em montagem, "teria podido [ao europeu do século XIX], simplesmente olhando-o, tomar consciência da natureza problemática de sua própria tradição cultural" (ibidem, p. 138). A emoção vivenciada por Bernadet, certamente, não implica uma totalização e compreensão de nossa tradição cultural. Entretanto, há nessa referência às emoções e às densidades que falam ao primitivo e ao arcaico uma valorização da dimensão dos afetos e das sensações, uma compreensão - além do verbalizável nascida na relação. Esse é o ponto central que, a nosso ver, torna potente a aproximação do filme ao pensamento warburguiano.

\section{Excessos emotivos no corpo veloz}

O recorte do filme que propomos dialoga com a prancha 40 do Atlas. Localizada na seção VI, que se intitula Fórmulas de páthos Dionisíacas, a prancha 40 trata das expressões em excesso, da Pathosformel referente à fuga, ao desespero, à defesa. No filme de Masagão, o recorte feito do conjunto de planos dura cerca de 48 segundos. De uma elaborada sequência com animais, que coloca em tensão a "supremacia" humana (um cavalo que sucumbe, uma lhama amarrada a uma bomba de gasolina, 
king kong no alto de um prédio nova-iorquino, o monólito de 2001, uma odisseia no espaço, uma rã que despenca do céu, uma galinha que levanta a pata ao entrar em contato com o timbre de voz humano, seguido de uma martelada em um parque de diversão e um caça níquel), inicia-se a parte que iremos analisar: nosso tableaux audiovisual recortado (Fig. 1). Uma nova melodia acompanha o início da sequência: surge um homem correndo com um pedaço de carne.

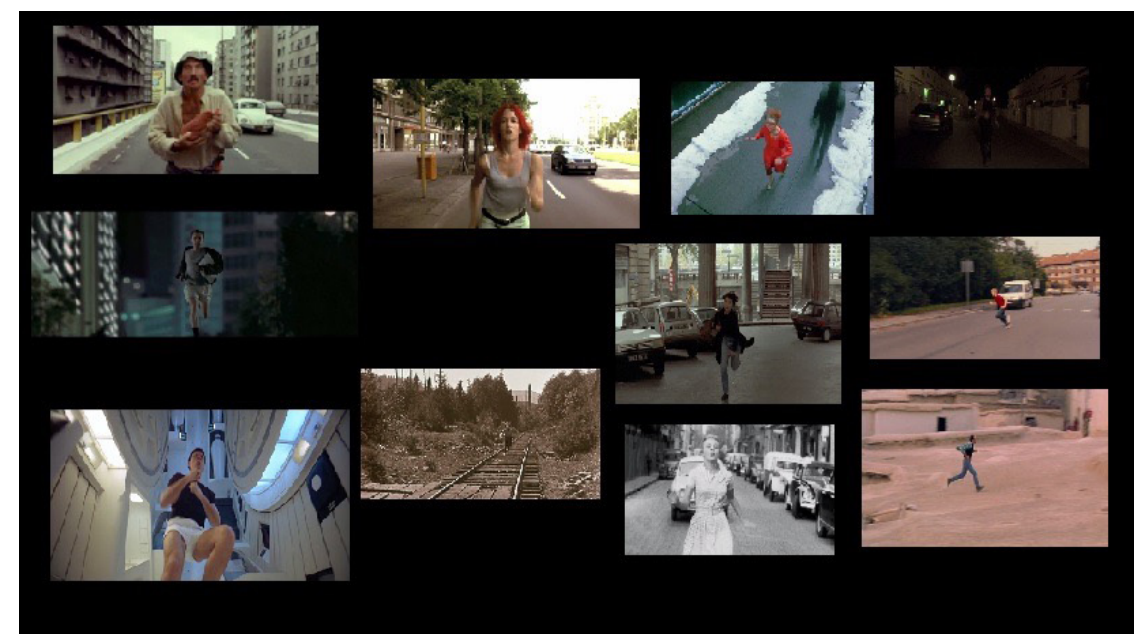

Fig. 1. Composição dos planos analisados.

Trata-se de Nho Quim, do filme A marvada carne (1985), de André Klotzel. Vale ressaltar, antes de tudo, que Ato, atalho e vento também funciona em um jogo entre conhecimento/desconhecimento das imagens de seu contexto original. Sabemos que, no filme de Klotzel, Nho Quim tinha dois desejos na vida: encontrar uma noiva e comer carne de vaca. E eis a imagem de Nho Quim correndo em fuga com um pedaço de carne entre os carros. Ele segura a carne com as duas mãos em um gesto que é tanto de reverência como de cuidado: seu desejo se materializou em condições adversas. Os conhecedores do filme original sabem que a carne que ele carrega foi furtada em meio a um motim contra um supermercado. Porém, no filme de Masagão temos apenas a fuga do personagem. É uma corrida solitária, rodeada por prédios altos e carros, que contrastam com a figura simples e provinciana do homem. Seu olhar está direcionado para o horizonte, para onde suas pernas avançam. Aquela corrida é um ato de sobrevivência, de luta contra a fome. A figuração do corpo em movimento, do rosto aflito, recobre uma condição fundamental de alimentação, e também um desejo culturalmente formado.

A fuga de Nho Quim com um pedaço de carne nas mãos dura cerca de 5 segundos, e é substituída por uma corrida ainda mais visceral de uma moça de cabelos vermelhos. 
O ambiente urbano é similar. A justaposição das imagem constrói um elo de ligação entre os dois corpos, que possuem proporções e enquadramentos similares. A corrida da mulher de cabelos vermelhos, a Lola, de Corra Lola, corra (1998), é uma corrida determinada, assim como a antecessora. Há uma energia nos movimentos, na pulsação do corpo, na aceleração da realidade cotidiana. A respiração acelerada cessa qualquer possibilidade de fala. Não se trata de uma instrospecção ou momento contemplativo. Entretanto, essa mudez é, ao mesmo tempo, uma verborragia do corpo, um grito corporal, uma vontade de estar lá onde não estou. O tempo é uma questão crucial na corrida de Lola, questão de vida ou morte. O corpo em suspensão e deslocamento veloz é uma Pathosformel da luta contra o tempo e a favor da vida (do namorado de Lola, no caso).

Os sete planos seguintes, de Acossado (1960) à Clube da Luta (1999), acompanham esse páthos da urgência, ainda que as fórmulas de cada personagem carreguem outros sentimentos, de acordo com certos detalhes. As mãos da personagem Patrícia, de Acossado, por exemplo, possui uma gesticulação particular do antebraço, que não acompanha a aerodinâmica de uma corrida, e imprimi um traço de descompasso ao corpo que corre. A cabeça levemente levantada e a boca entreaberta carregam uma teatralidade de desespero. Dentre esses sete planos, alguns estão enquadrados em planos mais abertos, onde o corpo é visto por inteiro e as expressões faciais perdem sua força em favor da exibição do espaço no qual o corpo se desloca.

O penúltimo plano dessa sequência possui uma inversão mais evidente na Pathosformel. Warburg notava, e evidenciava isso em seu Atlas, que as fórmulas não possuíam sentidos definidos e estanques. Na leitura que faz da inversão warburgiana, Erick Felinto afirma que:

É precisamente pelo fato de que as imagens têm uma vida e são dinâmicas ou seja, têm mobilidade - que as sensações por elas produzidas dependem de contexto e situação específicos. Essa língua imagética da gestualidade (Bildersprache der Gebärde) têm conteúdo expressivo modificável e pode mesmo, num processo denominado por Warburg de "Inversion", adquirir significados radicalmente opostos em diferentes ocasiões e concretizações. Desse modo, um gesto que antes indicava temor e medo pode, em outra manifestação imagética, indicar contemplação." (FELINTO, 2016, p. 22).

Eis que após essa montagem de imagens de corpos em fuga, a corrida assume claramente um novo sentido. Trata-se de um plano do filme 2001, uma odisseia no espaço, obra-prima de Stanley Kubrick. Nele, o personagem corre em uma espécie de esteira cilíndrica, que lembra as esteiras para ratos de laboratório. O personagem está dentro de uma espaçonave, e o plano reforça que ele está enclausurado. Mesmo para o espectador que não tenha visto o filme, fica claro que aquele corpo não está em fuga. Além disso, 
o movimento da corrida parece ser consciente e premeditado, ao contrário dos outros planos, que encenam uma imposição externa inevitável. A corrida do personagem, em 2001, possui uma dimensão fitness, que inverte completamente o sentido dos outros planos. O excesso, presente nos planos predecessores como desespero, urgência, temor, ali, evidencia confiança, determinação. Talvez o único traço que o conecte mais diretamente às imagens anteriores seja um páthos da solidão, que assume uma conotação bem explícita no último plano. Trata-se do filme Réquiem para um sonho (2000). Em uma tomada em plongée, que ajuda a reforçar um sentido de opressão, a personagem caminha entre vultos de pessoas. Ela não corre. Ao contrário, parece que as outras pessoas é que correm ao lado sem notá-la. O rosto da mulher carrega marcas claras de desesperança e sofrimento. Ela caminha contra o vento, e parece ser penosa essa caminhada. Seus cabelos e seu vestido vermelho reforçam essa dificuldade.

\section{Considerações finais}

A descrição e análise desse pequeno trecho, importante para fazer notar as nuances e particularidades estéticas do filme, não substitui, obviamente, a experiência de visualizá-las no contexto total da obra. Do modo como o fizemos, talvez tenhamos condicionado um olhar de intencionalidade que, certamente, o filme ultrapassa. Ainda que os blocos possam ser facilmente identificados, há inúmeras incursões sutis entre os planos cinematográficos que lampejam e nos colocam diante de puras sensações e afecções. Trata-se aqui de uma seleção arbitrária. A escolha desse recorte de poucos segundos é uma perspectiva que possibilita notar uma das facetas da proposta de Masagão a partir do pensamento de Warburg.

Embora haja certas inadequações entre o filme de Masagão e o pensamento/projeto de Warburg, brevemente elencadas ao longo do texto, ambos parecem compartilhar do desejo por aquilo que habita o entre. A montagem, em ambos os casos, é o recurso que possibilita a criação desse entre e desse acúmulo de tempos. No caso de Ato, atalho e vento, essa temporalidade é reforçada pelas diferenças materiais e qualitativas das imagens, como as granulações, os formatos, as imagens coloridas e em preto e branco. Nessa relação temporal, o gesto aparece como o elemento de destaque. A montagem de Masagão consegue iluminar, na aparição desses trechos de filmes consagrados pela narrativa, os gestos de uma cultura cinematográfica e instaura uma possível história patética do/no cinema.

Tal estratégia, obtida nesse processo de apropriação de imagens, parece ser um exercício valioso para se pensar e estudar, por imagens, aqueles que vamos nos tornando. Conforme afirma Carlinda Nuñez (2010, p. 55), "as fórmulas de páthos constituem um instrumento privilegiado para o tratamento analítico das formas cinéticas e da história dos afetos". Que venham novos filmes-tableaux, que nos permitam olhar para as imagens do passado e reconhecer, nos gestos, os movimentos misteriosos de nossa vida interior. 
Gabriel Malinowski é doutorando em Comunicação pela UERJ-RJ, mestre em Comunicação pela UFF-RJ (2010) e especialista em Comunicação e Imagem pela PUC-RJ. Foi docente em cursos de Cinema, Artes Visuais e Comunicação Social, coordenou o projeto de extensão Crescendo com Arte, que oferecia oficinas de cinema para alunos da rede pública do município de Barra Mansa. Atualmente é bolsista Capes e membro do grupo de pesquisa "Culturas Tecnológicas: Medialidades, Materialidades, Temporalidades", coordenado por Erick Felinto.

gabrielmalinowski@gmail.com

\section{Referências}

AGAMBEN, G. Notas sobre o gesto. Revista Artefilosofia. Ouro Preto, n.4, p. 09-14, 2008.

Aby Warburg e a ciência sem nome. Arte e ensaio, n.22, p. 132-143, 2011.

ATO, atalho e vento. Direção: Marcelo Masagão. 2014. 70 min. Disponível em: <https://vimeo. com/118703385>. Acesso em: 17 ago. 2017.

BERNARDET, J-C. Ato, atalho e vento. 24 out. 2014. Disponível em: <http://outraspalavras.net/ jcbernardet/author/jeanclaude/>.

COSTA, L. C. da. A gravidade da imagem: arte e memória na contemporaneidade. Rio de Janeiro: Quartet: FAPERJ, 2014.

DIDI-HUBERMAN, G. A imagem sobrevivente: história da arte e tempo dos fantasmas segundo Aby Waburg. Rio de Janeiro: Contraponto, 2013.

FELINTO, E. Flusser eWarburg: gesto, imagem, comunicação. Revista Eco-pós. Rio de Janeiro, v.19, n.1, 2016.

MICHAUD. P.-A. Aby Warburg e a imagem em movimento. Rio de Janeiro: Contraponto, 2013.

NUÑEZ, C. De onde menos se espera, daí é que vem: o silêncio como fórmula de páthos das "Musas pensantes". Revista Trama Interdisciplinar. v.1. n. 1. 2010.

SAMAIN, E. As "Mnemosyne(s)" de Aby Warburg: Entre Antropologia, Imagens e Arte. Revista Poiésis. Rio de Janeiro, n. 17, p. 29-51, 2011.

WARBURG, A. Histórias de fantasmas para gente grande. São Paulo: Companhia Das Letras, 2015.

Artigo recebido em 15 de setembro e aprovado em 03 de novembro de 2017. 